\title{
Utilization of organic refuse compost for agricultural production on material recycling society
}

\author{
S. Mishima ${ }^{1}$, A. Endo ${ }^{2}$, Y. Shirato ${ }^{1} \&$ S. D. Kimura ${ }^{3}$ \\ ${ }^{I}$ National Institute for Agro-Environmental Sciences, Japan \\ ${ }^{2}$ Tokyo College of Food Technology, Japan \\ ${ }^{3}$ Tokyo Agriculture and Technology University, Japan
}

\begin{abstract}
We estimated the amount of compost derived from livestock excreta, food refuse and sewage sludge as possible industrial organic resources, and the capacity of farmland to utilize these composts on national and regional scales in Japan in 2005. Japan could produce 11.9 Tg, 5.8 Tg and 2.0 Tg of livestock manure, food refuse compost and sewage sludge compost, respectively. The amount of manure required to maintain soil fertility was calculated as $40.0 \mathrm{Tg}$ cattle manure. This capacity would mean that farmland could utilize all organic refuse compost on a national scale, although the variation among regions in potential compost production and utilization capacity means that not all regions would be able to utilize all of their organic refuse compost. The potential for refuse recycling in regions with intensive livestock farming and/or a large population would be quickly exhausted. To reuse valuable fertilizer ingredients, especially phosphorus, in organic refuse, other means, such as extracting phosphorus from incineration ash and during sewage processing, should be considered.
\end{abstract}

Keywords: livestock excreta, food refuse, sewage sludge, compost, farmland.

\section{Introduction}

Environmentally sound material cycling is one of the requirements of environmentally sound material cycling, and is one of the requirements of a sustainable society. Agriculture has a role to both utilize and produce organic refuse, such as livestock excreta, food refuse and municipal sewage sludge. 
Because these organic refuses come from food and feed, composting them and applying them to farmland would be an acceptable way of recycling. However, excessive application of organic refuse compost causes a load on the environment (for example, contamination and eutrophication of ground and surface water by nutrient constituents), damages soil (for example, excessive potassium, change in $\mathrm{pH}$, undesirable enrichment by nutrients and organic matter) and crops (for example an excess of macro- and/or micro-nutrients, soilborne damage or growth suppression), and affects humans and livestock (for example blue baby syndrome, acidosis, grass tetany). Therefore, it is important that organic refuse compost is applied appropriately for sustainable agricultural production, in the correct amounts in relation to the capacity of farmland to utilize such refuse.

The quantity of organic refuse, its nutrient content and the capacity for recycling this refuse on to farmland on a nutrient ingredient basis on a national scale have been discussed. However, the capacity for recycling on a regional scale on a fresh material basis has not been discussed or evaluated. In this paper, we estimate the capacity of farmland to utilize organic refuse compost on national and regional scales in Japan in 2005. To discuss productivity potential of organic refuse compost, all organic refuses are assumed to be composted for application to farmland.

\section{Methods}

\subsection{Livestock excreta}

Numbers of dairy and beef cattle, pigs, and poultry (layers and broilers) in Japan, nationally and by region, were derived from the Statistical Yearbook of the Ministry of Agriculture, Forestry and Fisheries [1]. Livestock phosphorus (P) excretion per head was derived from Tsuiki and Harada [2]. Total livestock P excretion, nationally and by region, was derived from head numbers of each kind of livestock and their P excretion.

\subsection{Food refuse}

Food refuse per capita was calculated from the total amount of food refuse produced in Japan [3] divided by the Japanese national population. The amount of food refuse produced by region was calculated from the regional population [4] and food refuse produced per capita. The amount of $\mathrm{P}$ in food refuse was calculated from the water and $\mathrm{P}$ content of food refuse and amount of food refuse.

\subsection{Municipal sewage sludge}

National and regional populations who use municipal sewage were calculated from the population [4] and the proportion served by a municipal sewage system [5]. Sewage sludge per capita was obtained from the amount of sewage sludge produced [5] and the national population served by a municipal sewage system. 
The amount of sewage sludge by region was derived from the regional population served by municipal sewage system and sewage sludge per capita. The amount of $\mathrm{P}$ in sewage sludge was calculated from the water and $\mathrm{P}$ content of sewage sludge.

\subsection{Estimation of compost amount}

If $\mathrm{P}$ is not lost by composting, compost fresh weight can be calculated as follows,

$$
F W=\frac{R M P \times 100}{P \times(100-W)}
$$

where FW is fresh weight of compost, RMP is $\mathrm{P}$ content of raw material, $\mathrm{P}$ is $\mathrm{P}$ content of compost, and $\mathrm{W}$ is water content of compost.

\subsection{Application of compost to farmland}

The scenario for annual application of compost to farmland was as follows. For paddy rice field, compost application is assumed to be equivalent to twice the amount of rice straw removal, except for northern districts. The amount varied from 0 to $5.62 \mathrm{Mg}$ ha-1 according to district. Amount of removal was according to Rice Related Report [6]. In northern districts, compost is not applied to paddy fields because of the cool climate. Applications to upland field, orchard and forage field are assumed to be $10 \mathrm{Mg}$ ha- $1,7.5 \mathrm{Mg}$ ha- 1 and $20 \mathrm{Mg}$ ha-1, respectively [7-9]. These amounts are assumed to maintain farmland soil fertility and are assumed to be an acceptable amount for continued application annually, not as the maximum that could be utilized at a single year application of compost. These amounts are based on cattle manure: $1 \mathrm{Mg}$ of pig manure is assumed to be equivalent to $2 \mathrm{Mg}$ of cattle manure and $1 \mathrm{Mg}$ of poultry manure, food refuse compost and sewage sludge compost are assumed to be equivalent to $2.64 \mathrm{Mg}$ of cattle manure [7,8,10]. Later, the amount of compost is indicated as amount of fresh weight of cattle manure equivalent, unless otherwise stated.

\section{Results}

\subsection{Amount of refuse and the compost}

Results for livestock excreta, food refuse and sewage sludge and their composts material are shown in Tables 1 and 2.

\subsubsection{Livestock excreta and manure}

Total amount of livestock excreta was $89 \mathrm{Tg}$ fresh weight. Cattle, pig and poultry excrete 14.2 to $44.2,8.7$ to 15.6 and 0.21 to $0.58 \mathrm{~g}$ of $\mathrm{P}$ per day; therefore they excrete $34 \mathrm{Gg}, 40 \mathrm{Gg}$, and $42 \mathrm{Gg}$ of $\mathrm{P}$, respectively. Seventy percent of pig urine, equal to $15 \mathrm{Gg}$ of $\mathrm{P}$, was eliminated by disposal through sewage treatment. Cattle, pig and poultry manure contains $5.37 \%, 39.9 \%$ and $63.7 \%$ of water and $0.87 \%, 2.31 \%$ and $2.56 \%$ of $\mathrm{P}$, respectively. When all of the rest was composted, the amount of cattle, pig and poultry manure would be $7.7 \mathrm{Tg}, 2.1 \mathrm{Tg}$ and $2.1 \mathrm{Tg}$ 
Table 1: $\quad$ Outline of statistics in Japan and its regions.

\begin{tabular}{|c|c|c|c|c|c|c|}
\hline Region & Farmland $^{*}$ & Cattle $^{* * *}$ & $\operatorname{Pig}^{* *}$ & Poultry $^{* *}$ & Population $^{* * *}$ & Sewage $^{* * *}$ \\
\hline Japan & 46,938 & $4,402,000$ & $9,724,000$ & 279,905 & $127,756,815$ & $88,535,473$ \\
\hline Hokkaido & 11,687 & $1,305,200$ & 535,400 & 12,142 & $5,627,424$ & $4,912,741$ \\
\hline Aomori & 1,591 & 73,200 & 389,300 & 11,661 & $1,436,628$ & 699,638 \\
\hline Iwate & 1,566 & 160,800 & 395,700 & 20,788 & $1,385,037$ & 639,887 \\
\hline Miyagi & 1,380 & 124,900 & 238,300 & 6,682 & $2,359,991$ & $1,725,153$ \\
\hline Akita & 1,522 & 29,330 & 243,700 & 1,982 & $1,145,471$ & 583,045 \\
\hline Yamagata & 1,249 & 52,200 & 170,100 & 1,221 & $1,216,116$ & 783,179 \\
\hline Fukushima & 1,532 & 103,600 & 230,900 & 5,959 & $2,091,223$ & 890,861 \\
\hline Ibaraki & 1,773 & 89,200 & 625,100 & 13,173 & $2,975,023$ & $1,502,387$ \\
\hline Tochigi & 1,300 & 156,400 & 338,700 & 4,792 & $2,016,452$ & $1,113,082$ \\
\hline Gunma & 785 & 112,900 & 607,300 & 7,233 & $2,024,044$ & 882,483 \\
\hline Saitama & 848 & 40,100 & 139,600 & 5,632 & $7,053,689$ & $5,142,139$ \\
\hline Chiba & 1,334 & 88,500 & 541,700 & 11,703 & $6,056,159$ & $3,857,773$ \\
\hline Tokyo & 83 & 3,830 & 5,190 & 144 & $12,570,904$ & $12,369,770$ \\
\hline Kanagawa & 211 & 18,960 & 98,800 & 1,506 & $8,790,900$ & $8,307,401$ \\
\hline Niigata & 1,771 & 26,400 & 222,200 & 5,219 & $2,431,396$ & $1,291,071$ \\
\hline Toyama & 601 & 7,860 & 39,800 & 1,517 & $1,111,602$ & 801,465 \\
\hline Ishikawa & 445 & 9,140 & 37,100 & 1,627 & $1,173,994$ & 685,612 \\
\hline Fukui & 414 & 6,550 & 5,370 & 659 & 821,589 & 590,722 \\
\hline Yamanashi & 259 & 13,210 & 24,200 & 940 & 884,531 & 625,363 \\
\hline Nagano & 1,136 & 56,200 & 106,200 & 1,773 & $2,196,012$ & $1,370,311$ \\
\hline Gifu & 591 & 44,340 & 104,500 & 6,975 & $2,107,293$ & $1,083,149$ \\
\hline Shizuoka & 751 & 46,700 & 156,600 & 5,419 & $3,792,457$ & $2,430,965$ \\
\hline Aichi & 840 & 96,100 & 378,900 & 10,875 & $7,254,432$ & $2,720,412$ \\
\hline Mie & 633 & 37,400 & 133,000 & 6,354 & $1,867,166$ & $1,174,447$ \\
\hline Shiga & 546 & 22,550 & 13,300 & 898 & $1,380,343$ & $1,108,415$ \\
\hline Kyoto & 330 & 14,520 & 17,600 & 2,246 & $2,647,523$ & $2,303,345$ \\
\hline Osaka & 145 & 3,750 & 8,860 & 196 & $8,817,010$ & $7,847,139$ \\
\hline Hy ogo & 773 & 87,000 & 27,300 & 7,952 & $5,590,381$ & $5,484,164$ \\
\hline Nara & 233 & 8,680 & 12,500 & 896 & $1,421,367$ & 967,951 \\
\hline Wakay ama & 370 & 4,940 & 3,530 & 1,862 & $1,036,061$ & 148,157 \\
\hline Tottori & 356 & 33,700 & 73,300 & 2,673 & 606,947 & 339,890 \\
\hline Shimane & 395 & 45,900 & 37,900 & 1,335 & 742,135 & 253,810 \\
\hline Okayama & 710 & 59,300 & 34,900 & 8,632 & $1,957,056$ & 980,485 \\
\hline Hiroshima & 605 & 41,500 & 61,700 & 8,675 & $2,876,762$ & $1,846,881$ \\
\hline Yamaguchi & 515 & 23,590 & 26,200 & 4,289 & $1,492,575$ & 795,542 \\
\hline Tokushima & 324 & 38,620 & 42,000 & 4,264 & 809,974 & 93,147 \\
\hline Kagawa & 328 & 26,900 & 40,100 & 8,237 & $1,012,261$ & 370,488 \\
\hline Ehime & 569 & 28,080 & 225,300 & 4,232 & $1,467,824$ & 619,422 \\
\hline Kochi & 289 & 11,990 & 42,200 & 593 & 796,211 & 224,532 \\
\hline Fukuoka & 899 & 50,400 & 77,900 & 6,008 & $5,049,126$ & $3,544,486$ \\
\hline Saga & 560 & 67,170 & 85,400 & 3,393 & 866,402 & 338,763 \\
\hline Nagasaki & 513 & 102,100 & 195,700 & 3,854 & $1,478,630$ & 780,717 \\
\hline Kumamoto & 1,204 & 199,300 & 284,800 & 5,251 & $1,842,140$ & $1,015,019$ \\
\hline Ooita & 604 & 84,500 & 134,500 & 3,584 & $1,209,587$ & 485,044 \\
\hline Miyazaki & 702 & 288,900 & 863,600 & 22,384 & $1,152,993$ & 537,295 \\
\hline Kagoshima & 1,255 & 370,400 & $1,378,000$ & 30,277 & $1,753,144$ & 641,651 \\
\hline \multirow[t]{2}{*}{ Okinawa } & 393 & 84,820 & 269,900 & 2,109 & $1,360,830$ & 845,075 \\
\hline & $*: \mathrm{km}^{2}$ & \multicolumn{2}{|c|}{ **:head, capita } & \multicolumn{3}{|c|}{$* * *:$ population use sewage system } \\
\hline
\end{tabular}


Table 2: Amount of refuse composted material and farmland capacity to receive.

\begin{tabular}{|c|c|c|c|c|c|c|c|c|}
\hline Region & Cor & $\operatorname{ppost}(\mathrm{C}$ & & Capacity & In cattle & manure & eq.(Gg) & Type $^{*}$ \\
\hline & Livestock & Food & $\begin{array}{l}\text { Sewage } \\
\text { Sen }\end{array}$ & (Gg) & Livestock & Food & Sewage & \\
\hline Japan & 11,902 & 5,803 & 1,988 & 40,036 & 17,415 & 15,272 & 5,232 & $\mathrm{~A}$ \\
\hline Hokkaido & 2,850 & 256 & 110 & 17,076 & 3,107 & 673 & 290 & $\bar{A}$ \\
\hline Aomori & 276 & 65 & 16 & 1,067 & 492 & 172 & 41 & A \\
\hline Iwate & 477 & 63 & 14 & 1,201 & 750 & 166 & 38 & A \\
\hline Miyagi & 310 & 107 & 39 & 575 & 452 & 282 & 102 & $\mathrm{C}$ \\
\hline Akita & 119 & 52 & 13 & 518 & 202 & 137 & 34 & A \\
\hline Yamagata & 135 & 55 & 18 & 461 & 186 & 145 & 46 & A \\
\hline Fukushima & 260 & 95 & 20 & 620 & 390 & 250 & 53 & $\mathrm{C}$ \\
\hline Ibaraki & 412 & 135 & 34 & 1,341 & 738 & 356 & 89 & A \\
\hline Tochigi & 400 & 92 & 25 & 1,058 & 544 & 241 & 66 & A \\
\hline Gunma & 394 & 92 & 20 & 735 & 612 & 242 & 52 & $\mathrm{C}$ \\
\hline Saitama & 151 & 320 & 115 & 571 & 254 & 843 & 304 & $\mathrm{C}$ \\
\hline Chiba & 400 & 275 & 87 & 1,025 & 679 & 724 & 228 & $\mathrm{C}$ \\
\hline Tokyo & 11 & 571 & 278 & 79 & 15 & 1,503 & 731 & $\mathrm{C}$ \\
\hline Kanagawa & 82 & 399 & 187 & 192 & 126 & 1,051 & 491 & C \\
\hline Niigata & 142 & 110 & 29 & 360 & 255 & 291 & 76 & C \\
\hline Toyama & 38 & 50 & 18 & 149 & 72 & 133 & 47 & C \\
\hline Ishikawa & 42 & 53 & 15 & 107 & 74 & 140 & 41 & C \\
\hline Fukui & 18 & 37 & 13 & 129 & 30 & 98 & 35 & B \\
\hline Yamanashi & 38 & 40 & 14 & 179 & 56 & 106 & 37 & B \\
\hline Nagano & 145 & 100 & 31 & 819 & 188 & 263 & 81 & A \\
\hline Gifu & 151 & 96 & 24 & 434 & 267 & 252 & 64 & $\mathrm{C}$ \\
\hline Shizuoka & 167 & 172 & 55 & 512 & 277 & 453 & 144 & $\mathrm{C}$ \\
\hline Aichi & 355 & 330 & 61 & 555 & 592 & 867 & 161 & D \\
\hline Mie & 143 & 85 & 26 & 327 & 258 & 223 & 69 & $\mathrm{C}$ \\
\hline Shiga & 47 & 63 & 25 & 295 & 63 & 165 & 66 & A \\
\hline Kyoto & 52 & 120 & 52 & 154 & 90 & 316 & 136 & $\mathrm{C}$ \\
\hline Osaka & 13 & 401 & 176 & 76 & 18 & 1,054 & 464 & $\mathrm{C}$ \\
\hline Hyogo & 219 & 254 & 123 & 440 & 331 & 668 & 324 & $\mathrm{C}$ \\
\hline Nara & 31 & 65 & 22 & 106 & 48 & 170 & 57 & C \\
\hline Wakay ama & 22 & 47 & 3 & 230 & 45 & 124 & 9 & A \\
\hline Tottori & 90 & 28 & 8 & 199 & 132 & 73 & 20 & C \\
\hline Shimane & 93 & 34 & 6 & 141 & 119 & 89 & 15 & C \\
\hline Okayama & 189 & 89 & 22 & 270 & 316 & 234 & 58 & D \\
\hline Hiroshima & 153 & 131 & 41 & 234 & 285 & 344 & 109 & D \\
\hline Yamaguchi & 76 & 68 & 18 & 258 & 137 & 178 & 47 & C \\
\hline Tokushima & 95 & 37 & 2 & 223 & 144 & 97 & 6 & C \\
\hline Kagawa & 121 & 46 & 8 & 205 & 238 & 121 & 22 & D \\
\hline Ehime & 131 & 67 & 14 & 376 & 235 & 175 & 37 & C \\
\hline Kochi & 37 & 36 & 5 & 164 & 55 & 95 & 13 & A \\
\hline Fukuoka & 160 & 229 & 80 & 860 & 258 & 604 & 209 & C \\
\hline Saga & 133 & 39 & 8 & 623 & 184 & 104 & 20 & A \\
\hline Nagasaki & 218 & 67 & 18 & 520 & 306 & 177 & 46 & B \\
\hline Kumamoto & 418 & 84 & 23 & 1,194 & 539 & 220 & 60 & A \\
\hline Ooita & 187 & 55 & 11 & 539 & 257 & 145 & 29 & A \\
\hline Miyazaki & 712 & 52 & 12 & 982 & 1,108 & 138 & 32 & D \\
\hline Kagoshima & 987 & 80 & 14 & 1,439 & 1,596 & 210 & 38 & D \\
\hline Okinawa & 202 & 62 & 19 & 417 & 340 & 163 & 50 & $\mathrm{C}$ \\
\hline
\end{tabular}


of each type of manure by fresh weight and $17.4 \mathrm{Tg}$ in cattle manure equivalent on a national scale. The regions with the largest and the smallest amounts of manure were Hokkaido $(3,107 \mathrm{Gg})$ and Tokyo $(15 \mathrm{Gg})$, respectively. Hokkaido had the largest number of livestock and Tokyo the lowest number among the regions (Table 2).

\subsubsection{Food refuse and its compost}

The amount of food refuse was $22 \mathrm{Tg}$ on a national scale. It contained $80 \%$ of water and $0.6 \%$ of P, i.e., food refuse contained $26 \mathrm{Gg}$ of $\mathrm{P}$. Food refuse compost contained $1.22 \%$ of $\mathrm{P}$ and $62.7 \%$ of water. Therefore, if all food refuse was composted, the amount of food refuse compost would be $5.8 \mathrm{Tg}$ on a national scale. Food refuse compost can be produced at $45.4 \mathrm{~kg}$ per capita. The region with the largest and was Tokyo (571 Gg as food refuse compost) and with the smallest budget was Tottori (28 Gg as food refuse compost) (Table 2), a difference that resulted from their different populations (Table 1).

\subsubsection{Sewage sludge and its compost}

The amount of sewage sludge was $75 \mathrm{Tg}$ on a national scale. It contained $97 \%$ of water and $0.39 \%$ of P. Therefore it corresponded to $20 \mathrm{Gg}$ P. Sewage sludge compost contained $52 \%$ of water and $2.12 \%$ of P. If all sewage sludge was composted, the amount of sewage sludge compost would be $2.0 \mathrm{Tg}$ on a sewage sludge compost basis, which corresponds to $5.2 \mathrm{Tg}$ of cattle manure equivalent. Sewage sludge had high water content (97\%). However, water and organic matter loss during composting meant that the amount of sewage sludge compost was much smaller than that of sewage sludge, the raw material. Therefore, composting is an effective way of reducing the amount of compost. One sewage system user would produce $22.5 \mathrm{~kg}$. Tokyo produced the greatest amount of sewage sludge compost (278 Gg in sewage sludge compost) and Tokushima the least ( $2 \mathrm{Gg}$ in sewage sludge compost) (Table 2). The variation in amount of compost was a result of the differences in the population and the population served by the sewage system (Table 1).

\subsubsection{Amount of compost in cattle manure equivalent}

The amounts of all manures and composts were converted to cattle manure equivalents. The amounts of livestock manure, food refuse compost, sewage sludge compost and total refuse on a national scale were $17.4 \mathrm{Tg}, 15.3 \mathrm{Tg}, 5.2$ $\mathrm{Tg}$, and $37.9 \mathrm{Tg}$ in cattle manure equivalents. The maximum was observed in Hokkaido (4,070 Gg cattle manure equivalent) and the minimum in Fukui (163 Gg cattle manure equivalent). Hokkaido had the largest number of livestock and Fukui the smallest of livestock, population and population served by a sewage system (Table 2).

\subsection{The amount farmland receive compost}

Japan had 1,702,000 ha, 1,337,870 ha, 314,500 ha and 1,030,000 ha of paddy rice field, upland field, orchard and forage field, respectively; these areas received $4.1 \mathrm{Tg}, 13.4 \mathrm{Tg}, 2.4 \mathrm{Tg}$ and $20.1 \mathrm{Tg}$ of compost, respectively. In total, Japanese farmland would be able to utilize $40.0 \mathrm{Tg}$ of compost to maintain soil 
fertility (Table 2). The largest and the smallest utilization capacities were recorded in Hokkaido $(17,076 \mathrm{Gg})$ and Osaka $(76 \mathrm{Gg})$, respectively. Hokkaido has a large forage field area. Osaka is small region with a small area of farmland (Table 2).

The amount of compost applied to Japanese farmland exceeded the total production of organic refuse compost (37.2 Tg). However, uneven regional distribution of organic refuse compost meant that some regions could not fully utilize all compost produced. When livestock manure, food refuse compost and sewage sludge compost were applied to farmland, 14 regions utilized all compost (Type A), 3 regions utilized all of livestock manure and food refuse compost (Type B), 24 regions utilized all livestock manure (Type C), while 6 regions produced more livestock manure than they could utilize (Type D) (Table 2).

\section{Discussion}

Several estimates have been made of the amount of organic refuse produced in Japan and the capacity of farmland to utilize it.

Shiga [11] estimated in 1990 the amount of livestock nitrogen (N) excretion and the amount of excreta farmland can utilize on the basis of the amount of $\mathrm{N}$, concluding that all livestock excreta would be utilized for maintaining soil fertility and could partly substitute for chemical fertilizer on a national scale in Japan. This estimation, which did not exclude $\mathrm{N}$ loss by composting, is one of the recent estimates of the relationship between the amount of livestock excreta and the capacity farmland to utilize it.

Ikumo et al. [12] noted the balance between the amount of livestock excreta $\mathrm{N}$ and the utilization capacity of farmland in each of the 47 regions of Japan, and indicated the surplus or deficiency of livestock excreta N. Although their estimated level of livestock excreta application to farmland was near to our estimation, the number of regions showing a deficiency differed. This difference was caused by the difference in $\mathrm{N}$ estimated on a fresh weight basis, weighting the amount of excreta according to type of livestock, whether or not excreta was applied to farmland, including $\mathrm{N}$ disappearance during composting in spite of $\mathrm{N}$ basis estimation, and so on.

The Japan Organic Resource Association [13] estimated nutrient constituents in various kinds of organic refuse on a national scale in Japan, and made a trial calculation in which all nutrients derived from organic refuse substituted chemical fertilizer. Although this is the most comprehensive nutrient budget estimation on organic refuse in Japan, it did not take into account uneven distribution of organic refuse among regions.

The Ministry of Agriculture, Forestry and Fisheries (MAFF) initiated a study on the lowest possible application of compost to farmland needed to maintain soil organic matter and fertility [14]. This study suggested that paddy field rice, upland field, vegetable field, and orchard should receive 3, 5-25, 10-25, 10$15 \mathrm{Mg}$ ha-1 of cattle manure, respectively [14]. On the basis of this study, our rough estimation suggests that $42.3 \mathrm{Tg}$ of cattle manure would be needed to maintain soil organic matter and soil fertility. This level of manure application is 
near to our estimation, assuming compost is applied every year to sustain soil fertility. The MAFF did not estimate a compost budget for Japan and did not take into account the variation in compost requirements among regions.

Our estimate of the amount of compost has a high level of uncertainty. For example, livestock manures have a $95 \%$ confidence range of $50-60 \%$ against mean $P$ content [15], i.e., the amount of manure would have a $95 \%$ chance of varying by $50-60 \%$ on a fresh weight basis against our estimation. The amounts of compost that farmland can utilize per year also range widely, for example upland field can utilize 5-15 Mg ha ${ }^{-1}$ of cattle manure. We included in our calculations only livestock manure, food refuse compost and sewage sludge compost, because their raw materials are abundant on livestock farms and in waste and sewage treatment centres, and are therefore easy to compost on an industrial scale. Although human waste is also a valuable organic refuse resource, it is dispersed. However our estimates had uncertain and limiting the item of organic refuses, this will be one of the test estimations and one of the proposal plans for distributing to utilizing organic refuse resource in regional native farmland or to terminal disposal processing.

Livestock manure is relatively easy to obtain and use, is an acceptable material for crop farmers to use, and is also accepted socially and industrially. However, 6 regions were categorized as Type D (only part of livestock manure can be utilized by farmland) (Table 2). Because livestock farms do not always use much local land and are independent of crop farms, an excess of livestock manure is available. In these circumstances, some restriction on livestock farming or an expansion of farmland for livestock farming would be needed for all livestock manure to be utilized. The other 24 regions can utilize all livestock manure (Type $\mathrm{C}$, Table 2), which means the amount of manure produced and utilized is in balance.

Gaining acceptance for the application of food refuse compost to farmland will be the next step. Some independent organizations or food-related companies make food refuse compost for local farms or on contract to farms, to reduce waste disposal and to create an environmentally sound recycling system. However, the relationship between the organic refuse budget and farmland utilization capacity needed to maintain soil fertility needs further study. The nutrient ingredient or fresh material budget approach would be important and would be needed to explain the rationale of these activities. Type B (all livestock manure plus food refuse compost can be utilized) includes 3 regions with low populations.

Utilization of sewage sludge compost has been discussed in the past. However, it is not yet an accepted agricultural practice in Japan because sewage sludge is contaminated by high concentrations of heavy metals, because of acidification or alkalinization of farmland soil with large applications, and because people reject the concept. Type A (livestock manure plus food refuse compost and sewage sludge compost can be utilized) includes 14 regions with large areas of farmland and low populations.

Organic refuse disposal causes problems in regions with high populations, especially with small areas of farmland in relation to population. Utilizing 
compost for food and feed production in agriculture is not always environmentally sound and the potential for recycling would be quickly exhausted. However, P in organic refuse is very valuable. Extracting P from incineration ash of food refuse and sewage sludge and from sewage processing would be one way of utilizing $P$ in such refuse.

\section{References}

[1] Ministry of Agriculture, Forestry and Fisheries, The $81^{\text {st }}$ statistical yearbook of Ministry of Agriculture, Forestry and Fisheries, Association of Agriculture and Forestry Statistics: Tokyo, pp. 145-233, 2007.

[2] Tsuiki M. \& Harada, Y., A program for estimation of nitrogen discharge by livestock. Animal Husbandry, 44, pp.773-776, 1994. (in Japanese)

[3] Ministry of Agriculture, Forestry and Fisheries. Biomass Japan Total Strategy, www.maff.go.jp/j/biomass/pdf/h18_senryaku.pdf (in Japanese)

[4] e-Stat. www.e-stat.go.jp/SG1/estat/List.do? bid=000001007609\&cycode $=0$ (in Japanese)

[5] Japan Sewage Works Association, Sewage Works Statistics. Japan Sewage Works Association: Tokyo, p. 314, 2008. (in Japanese)

[6] Ministry of Agriculture, Forestry and Fisheries (MAFF), Rice Related Report, MAFF: Tokyo, p. 205, 2006. (in Japanese)

[7] Yamaguchi, T., Self staffing organic fertilizer -Cattle wastes-. Compendium of Agricultural Technology Soil Fertility Part 7-1, ed. Nosangyosonbunkakyokai, Nosangyosonbunkyakyokai: Tokyo, pp. 286292, 2008. (in Japanese)

[8] Yamaguchi, T. Self staffing organic fertilizer -Pig wastes-. Compendium of Agricultural Technology Soil Fertility Part 7-1, ed. Nosangyosonbunkakyokai, Nosangyosonbunkyakyokai: Tokyo, pp. 293294, 2008. (in Japanese)

[9] Hokkaido, Hokkaido Fertilization Guide. Hokkaido: Sapporo, p. 202, 2002. (in Japanese)

[10] Mishima, S., Endo, A., Shirato, Y. \& Kimura, S. D., Quantity of organic refuse resources in Japanese regions and receiving capacity of organic refuse derived compost by local farmland. Jpn J. Soil Sci. Plant Nutr. Accepted. (in Japanese with English summary)

[11] Shiga, K., Capacity of organic resources application to farmland and livestock wastes, Research and development centre for daily farming, Sapporo, pp. 25-45, 1994. (in Japanese)

[12] Ikumo, H., Morie, M., Yamamoto, N. \& Yamaguchi, T., Research survey and technological development for recyclable use of organic resources, especially livestock waste - The research outline of research project team 6 and team 5 of National Agricultural Research Centre -. Miscellaneous Publication of the National Agricultural Research Centre, 7, pp. 93-117, 2007. (in Japanese with English summary)

[13] Japan Organic Resource Association, Present state and issue of organic wastes recycling, MAFF: Tokyo, pp. 29-54, 1999. (in Japanese) 
[14] Ministry of Agriculture, Forestry and Fisheries. Discussion of driving sustainable agriculture, www.maff.go.jp/j/study/kankyo_hozen /pdf/h2004_report.pdf (in Japanese)

[15] Mishima, S., Akiyama, H., Yagi, K. \& Kohyama, K., The trend of livestock manure qualities and estimation of nitrogen loss rate by composting. Jpn. J. Soil Sci. Plant Nutr. 79(4), pp. 370-375. (in Japanese) 